\title{
Concomittant Liver Transplantation and Low Anterior Resection in Patient with Neuroendocrine Tumor and Chronic Hepatitis B Infection
}

\author{
Adem Tuncer $^{1}$ (D) $\cdot$ Zeki Ogut $^{1} \cdot$ Sertac Usta ${ }^{1} \cdot$ Sami Akbulut $^{1} \cdot$ Tevfik Tolga Sahin $^{1} \cdot$ Sezai Yilmaz $^{1}$
}

Accepted: 23 September 2021 / Published online: 6 October 2021

(c) Springer Science+Business Media, LLC, part of Springer Nature 2021

\section{Introduction}

Neuroendocrine tumors (NETs) are epithelial neoplasms that originate from the enterochromaffin cells. They have various biologic behaviors, and they are usually located in pancreas and small bowel. Rectal localization is relatively uncommon. The incidence of gastro-entero-pancreatic NET (GEPNET) is increasing together with extensive and elective use of upper gastrointestinal endoscopy [1,2]. The NET has insidious behavior and therefore diagnosed at a later stage when the disease is metastatic. Liver is the most frequent site of metastasis for NETs (46-93\%) [1].

NETs become symptomatic depending on the tumor burden and the level of hormone secretion. In the USA, rectal NETs make up $18 \%$ of the all the NETs and make up onethird of all the gastrointestinal NETs [2]. Majority of these lesions are diagnosed in the early stages. The 5 -year survival rates are reported to be $88 \%$, and the prognosis is relatively good [1]. Surgery is the only means of cure in GEP-NETs [3]. Various therapeutic options including liver resection can be applied for the treatment of liver metastasis of NETs. Liver transplantation for unresectable liver metastasis of NETs is an accepted therapeutic modality [4]. In the present study, we present a case with NETs and hepatitis B virus (HBV)-related cirrhosis who received synchronous living donor liver transplantation (LDLT) and low anterior resection (LAR) for rectal resection for NETs. In our knowledge, this was the first case in the literature.

Adem Tuncer

ademtuncer89@hotmail.com

1 Liver Transplant Institute and Department of Surgery , Faculty of Medicine, Inonu University, 44280 Malatya, Turkey

\section{Case Report}

A rectal mass was detected during colonoscopy in a 62-year-old male patient with chronic liver disease due to HBV (Fig. 1). Analysis of the biopsy specimen showed that it was a NET. The patient had a regulated diabetes mellitus. The patient had no history of intractable ascites, but his history showed that he suffered from two episodes of life-threatening variceal bleeding. The patient received antiviral treatment, and his HBV DNA and hepatitis D virus RNA were negative. Physical examination was unremarkable. The clinical and laboratory characteristics of the patient are summarized in Table 1.

The abdominal tomography showed that the liver had shrunken with a heterogenous and lobulated liver parenchyma. Also, there was ascites that had $6.5 \mathrm{~cm}$ in thickness in tomographic sections. Also, there was a mural thickness in the rectum. Ga-68 DOTA scintigraphy was performed for surveillance of metastatic lesion which showed that only rectum was involved together with a lymph node in the mesorectum (SUV-Max: 44.5). There was no metastatic lesion in the liver either. Therefore, we decided to perform simultaneous LDLT and low anterior resection for the patient.

Intraoperatively, we initially performed LDLT which was followed by low anterior resection for NET. We decided to perform a sigmoid loop colostomy to provide protection for the colon anastomosis due to concomitant two major operations, prolonged operative duration, and coagulopathy. We performed our routine antibiotic prophylaxisto the patient. Immunosuppressive treatment included methylprednisolone $(2 \times 100 \mathrm{mg})$ and mycophenolatemofetil $(2 \times 1000 \mathrm{mg})$ which was started on postoperative first day. Tacrolimus $(2 \times 1 \mathrm{mg})$ was started on postoperative third day. The dose of tacrolimus was tapered according to the trough levels. Oral intake was started on postoperative 2 nd day after the 


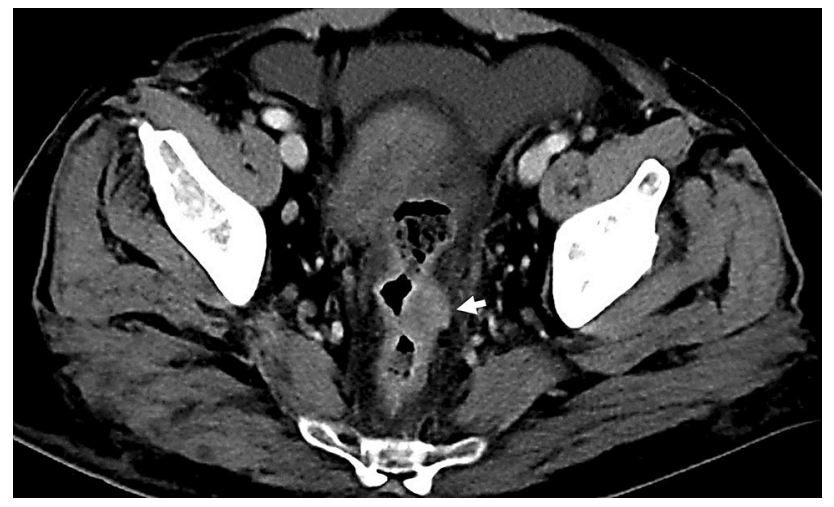

Fig. 1 Axiall pelvic computed tomography shows that a small lesion compatible with tumor originating from left rectal wall

discharge of the colostomy. The patient was discharged on postoperative 11th day.

The explant pathology showed that liver was nodular and advanced fibrosis but had no malignant metastasis. Histopathology of the hilar lymph node showed reactive hyperplasia. The rectal resection material was $12.5 \mathrm{~cm}$. The dimensions of the rectal mass were $1.8 \times 1.2 \times 1.3 \mathrm{~cm}$, and the proximal and distal surgical margins were negative. The tumor was grade II rectal NET. The tumor infiltrated perirectal adipose tissue and also had lympho-vascular and perineural invasion. The meso-rectal lymph node showed reactive changes. Synaptophysin, chromogranin A, and CD56 immunostaining was extensively positive. CEA staining was patchy positive, and Ki 67 proliferative index was 15-20\%.

The patients were followed monthly for the first postoperative 6 months. In the second postoperative 6 months, the follow-up was once in every 3 months. Later the follow-up

Table 1 The preoperative clinical and laboratory characteristics of the patient is summarized

\begin{tabular}{llll}
\hline MELD score & 21 & AST $(\mathbf{I U} / \mathbf{m L})$ & 38 \\
\hline BMI $\left(\mathrm{kg} / \mathrm{m}^{2}\right)$ & 29 & ALT $(\mathbf{I U} / \mathbf{m L})$ & 21 \\
HBSAG & 2396 & ALP $(\mathbf{I U} / \mathbf{m L})$ & 266 \\
HBV DNA PCR & Negative & GGT $(\mathbf{I U} / \mathbf{m L})$ & 55 \\
HDV RNA PCR & Negative & CA-125 & 142 \\
ANTI-HAV & Positive & Na $(\mathbf{m m o l} / \mathbf{L})$ & 128 \\
Hgb $(\mathrm{g} / \mathrm{dL})$ & 9.9 & Albumin $(\mathbf{g} / \mathbf{d L})$ & 1.9 \\
INR & 1.32 & Total bilirubin $(\mathbf{m g} / \mathbf{d L})$ & 2.2 \\
Creatinine & 0.81 & & \\
\hline
\end{tabular}

MELD score the model for end-stage liver disease score, $B M I$ body mass index, HBSAG hepatitis $\mathrm{B}$ surface antigen, $H B V D N A P C R$ hepatitis B virus DNA polymerase chain reaction, HDV RNA PCR hepatitis delta virus RNA polymerase chain reaction, ANTI-HAV hepatitis A virus antibody, $\mathrm{Hg} b$ hemoglobin, INR international normalized ratio, $A S T$ aspartate aminotransferase, $A L T$ alanine amino transferase, $A L P$ alkaline phosphatase, $G G T$ gamma glutamyl transferase, CA-125 cancer antigen $125, N a$ sodium routine was two times a year. The closure of the loop colostomy was delayed to postoperative 20th month due to the COVID-19 pandemic. The patient is now in good condition without any recurrence 24 months after the surgery.

\section{Discussion}

The treatment of end-stage liver disease is liver transplantation. The studies have shown patients transplanted for NET liver metastasis had comparable outcome to the patients with HCC within Milan criteria [5]. The patients are required to have at least 2 years following primary surgery for NET, and the disease should be confined to liver at the time of liver transplantation [6].

Majority of the rectal NET are small and localized to the mucosa and submucosa. Majority of the cases are dormant and symptomatic. However, as the tumor size and invasion depth increases, the risk of metastasis and aggressive biologic behavior increases. This has an effect on the postoperative outcome of these tumors and therefore. Early diagnosis has paramount importance for a favorable postoperative prognosis [7]. The definitive treatment of rectal NETs is resection. European Society of Medical Oncology guidelines state that surgery is the primary treatment of gastrointestinal NETs [8]. The 5-year survival rates of patients with rectal NET is $80-100 \%[9,10]$. Smaller tumors can be treated with endoscopic mucosal resection, transanal minimally invasive surgery. However larger tumors $(>2 \mathrm{~cm})$ or tumors that penetrate and extend through muscularispropria require low anterior resection and abdominoperineal resection [11].

In the present study, we performed concomitant LDLT and low anterior to patients with HBV related end stage liver disease and rectal NET. The majority of early postoperative infective complications (30-40\%) observed following liver transplantation is intraabdominal sepsis. This is due to the fact that biliary and gastrointestinal surgeries are contaminated surgeries [12]. We took every necessary precaution to prevent abdominal sepsis in a dismal surgical environment. The patient is now in postoperative second year with and uneventful postoperative follow-up. Our literature search has shown that there is only one reported case with concomitant liver transplantation and resection [13]. This was the case for our patient, and only rectal resection may lead to decompensation of the patient due to surgical trauma. On the other hand, performing LDLT would be contraindicated due to high risk of tumor progression due to immunosuppressive therapy. For this reason, we performed both LDLT and LAR in the same session. Portal clamping during liver transplantation causes edema in the colon. Since this edema will affect the anastomosis safety, we first performed LDLT and then LAR. 
In conclusion, the present study shows that concomitant liver transplantation and resection for gastrointestinal NET can be performed under strict selection. The characteristics of the patient in the present study showed that if the tumor has favorable biological characteristics, localized to primary site, and the liver failure is unrelated to the NET, then synchronous operations can be performed to the patients because staged procedure has definitive risks that would preclude definitive treatment and survival.

Author Contribution A. Tuncer, Z. Ogut, and S. Usta conceived and designed research. S Akbulut, TT Sahin, and S. Yilmaz conducted the research. A. Tuncer, S. Usta, Z. Ogut Z, and S. Akbulut contributed to data extraction. All authors wrote the manuscript. All authors read and approved the manuscript.

Availability of Data and Material Data sharing is not applicable to this article as no new data were created.

Code Availability Not applicable.

\section{Declarations}

Ethical Approval All procedures performed in the report were in accordance with the ethical standards of the institutional and/or national research committee and with the 1964 Helsinki Declaration and its later amendments or comparable ethical standards.

Informed Consent Informed consent including publication of photographs in medical journals was obtained from the participant of this study.

Conflict of Interest The authors declare no competing interests.

\section{References}

1. Harring TR, Nguyen NT, Goss JA, O'Mahony CA. Treatment of liver metastases in patients with neuroendocrine tumors: a comprehensive review. Int J Hepatol. 2011;2011: 154541. https://doi. org/10.4061/2011/154541.

2. Stier MW, Chapman CG, Shamah S, Donboli K, Yassan L, Waxman I, Siddiqui UD. Endoscopic resection is more effective than biopsyor EUS to detect residual rectal neuroendocrine tumor. EndoscInt Open. 2021;9:E4-8. https://doi.org/10. 1055/a-1300-1017.

3. Spychalski M, Koptas W, Zelga P, Dziki A. Role of endoscopic submucosal dissection in treatment of rectal gastroenteropancreatic neuroendocrine neoplasms. PrzGastroenterol. 2017;12:17-21. https://doi.org/10.5114/pg.2016.64635.
4. Fan ST, Le Treut YP, Mazzaferro V, Burroughs AK, Olausson M, Breitenstein S, Frilling A. Liver transplantation for neuroendocrine tumour liver metastases. HPB (Oxford). 2015;17:23-8. https://doi.org/10.1111/hpb.12308.

5. Gedaly R, Daily MF, Davenport D, McHugh PP, Koch A, Angulo P, Hundley JC. Liver transplantation for the treatment of liver metastases from neuroendocrine tumors: an analysis of the UNOS database. ArchSurg. 2011;146:953-8. https://doi.org/10.1001/ archsurg.2011.186.

6. Bachir NM, Larson AM. Adult liver transplantation in the United States. Am J MedSci. 2012;343:462-9. https://doi.org/10.1097/ MAJ.0b013e3182308b66.

7. Yu YJ, Li YW, Shi Y, Zhang Z, Zheng MY, Zhang SW. Clinical and pathological characteristics and prognosis of 132 cases of rectal neuroendocrine tumors. World J GastrointestOncol. 2020;12:893-902. https://doi.org/10.4251/wjgo.v12.i8.893.

8. Norton JA, Kivlen M, Li M, Schneider D, Chuter T, Jensen RT. Morbidity and mortality of aggressive resection in patients with advanced neuroendocrine tumors. Arch Surg. 2003;138:859-66. https://doi.org/10.1001/archsurg.138.8.859.

9. Magni E, Botteri E, Ravenda PS, Cassatella MC, Bertani E, Chiappa A, Luca F, Zorzino L, Bianchi PP, Adamoli L, Sandri MT, Zampino MG. Detection of circulating tumor cells in patients with locally advanced rectal cancer undergoing neoadjuvant therapy followed by curative surgery. Int J Colorectal Dis. 2014;29:1053-9. https:// doi.org/10.1007/s00384-014-1958-Z.

10. Cusati D, Zhang L, Harmsen WS, Hu A, Farnell MB, Nagorney DM, Donohue JH, Que FG, Reid-Lombardo KM, Kendrick ML (2012) Metastatic nonfunctioning pancreatic neuroendocrine carcinomato liver: surgical treatment and outcomes. J AmCollSurg. 215:117-24; discussion 124-5. https://doi.org/10.1016/j.jamcollsurg.2012.05. 002. PMID: 22726741.

11. Caplin M, Sundin A, Nillson O, Baum RP, Klose KJ, Kelestimur F, Plöckinger U, Papotti M, Salazar R, Pascher A, Conference BC, participants, . ENETS Consensus Guidelines for the management of patients with digestive neuroendocrine neoplasms: colorectal neuroendocrine neoplasms. Neuroendocrinology. 2012;95:88-97. https://doi.org/10.1159/000335594.

12. Mehrabi A, Fonouni H, Wente M, Sadeghi M, Eisenbach C, Encke J, Schmied BM, Libicher M, Zeier M, Weitz J, Büchler MW, Schmidt J. Wound complications following kidney and liver transplantation. Clin Transplant. 2006;20(17):97-110. https://doi. org/10.1111/j.1399-0012.2006.00608.x.

13. Abreu de Carvalho LE. Troisi R, de Hemptinne B (2009) Living donor liver transplantation combined with Whipple's procedure for metastatic gastrinoma: a clinical case with 5 years follow-up. Acta Chir Belg. 2009;109:498-500. https://doi.org/10.1080/00015458. 2009.11680468.

Publisher's Note Springer Nature remains neutral with regard to jurisdictional claims in published maps and institutional affiliations. 